\title{
Volunteer Retention Motives and Determinants across the Volunteer Lifecycle
}

\begin{abstract}
The focus of the paper is on better understanding volunteer retention. A broad-based survey of fourteen Australian nonprofit organizations develops an expanded quantitative model of volunteer retention by adding two new antecedents: values-congruency and altruistic motives to previous modelling. The study generates a more comprehensive set of rankings of volunteer retention motives, with altruism receiving top ranking. Using exploratory factor analysis, the study develops a new three-item perspective of altruism, combining helping, service and the cause. A new fourphase framework of the volunteer lifecycle is also developed. Investigating changes in retention motives over the life cycle reveals a major and unexpected finding, that the altruistic motive may actually become more important as volunteers move through the lifecycle.
\end{abstract}

\section{Keywords}

Volunteer lifecycle; volunteer retention; determinants of retention; altruism; nonprofit organizations 


\section{Volunteer Retention across the Volunteer Lifecycle: Motives and Determinants}

\section{Introduction}

Volunteers make a major contribution, with a 2010 (USA) Bureau of Labor Statistics estimate of US $\$ 239$ billion (Haski-Leventhal et al., 2011). In Australia in 2014, 31 percent of the population had volunteered in the previous year (ABS, 2014). Volunteering is virtually synonymous with the nonprofit sector. Despite the criticality of volunteers, surprisingly there is a limited coherent understanding of why volunteers join, stay or exit nonprofit organizations. At least two major reviews of the literature (Locke et al. 2003; Smith \& Cordery, 2010) are generally inconclusive as to even a ranking of factors most influential on volunteer behaviour.

A further review of the volunteer literature indicates that volunteer retention is the most neglected aspect of the volunteer lifecycle (Wilson, 2012). The focus of the current paper is three-fold: providing a better empirical explanation of volunteer retention; providing a more comprehensive ranking of the motives for retention; and providing a better understanding of how retention motives change over the different phases of the active volunteer lifecycle. These three aims formulate as three research questions.

To address the aim, the paper uses a quantitative study of volunteers in a diverse Australian sample of nonprofit organizations. Following from the literature review, the methodology for the study is explained, and then the preliminary and main results are presented. A detailed discussion follows, then the implications for nonprofit management are explored, and the conclusions highlight the major contributions ensuing from the study. 


\section{Literature Review}

Several literatures inform this study, traversing empirical models of volunteer retention, motives for volunteer retention, the volunteer lifecycle and changing retention motives over the volunteer lifecycle.

\section{Empirical models of volunteer retention}

A central purpose of the paper is to develop a more refined model of voluntary retention, one that better explains the variance in voluntary retention. Such purpose leads to our first research question:

RQ1: How can refined empirical models provide a greater statistical understanding/explanation of the variance in volunteer retention?

Existing empirical models of volunteer retention emphasize volunteer work satisfaction and organizational commitment (Bennett \& Barkensjo, 2005; Jensen \& McKeage, 2015). Both work satisfaction and organizational commitment are major indicators of the quality of the volunteer work experience and thus it is understandable that they are major determinants of volunteer retention, that is, the willingness of the volunteer to continue working for the nonprofit organization. Essentially, the dominance of work satisfaction and organizational commitment as determinants of volunteer retention can be represented as the prevailing fundamental model, the starting position for the paper. This approach gives the first two null hypotheses: 
H1: That a fundamental model of volunteer retention that includes work satisfaction will not have any effect on volunteer retention.

$\mathrm{H} 2$ : That a fundamental model of volunteer retention that includes organizational commitment will not have any effect on volunteer retention.

Building on the fundamental model of volunteer retention, the paper considers adding other determinants. The literature suggests a third possible determinant, namely the extent to which the values of the volunteer match those of the organization. Values-congruency is likely to be important in all types of organization but is particularly relevant in a nonprofit context because values are so important in such organizations. Support for including values-congruency as a determinant comes from several studies, including Locke et al. (2003), Randle and Dolnicar (2011) and Smith and Cordery (2010). Thus, Null Hypothesis 3 becomes:

H3: That an expanded model of volunteer retention that adds volunteer-organizational selfcongruity as an explanatory variable, does not add to the statistical explanation of volunteer retention.

Finally, the paper considers a potentially second new determinant of volunteer retention, namely explicit volunteer motives to remain with the organization. Although the literature discusses the motives for volunteer retention, previous empirical models of volunteer retention have not included them as a determinant. To address this shortfall, the study adds a fourth null hypothesis: H4: That an expanded model of volunteer retention that adds volunteer explicit motives as an explanatory variable, does not add to the statistical explanation of volunteer retention. 
In summary, Research Question 1 is addressed through four hypotheses, two of which are part of the status quo fundamental model of volunteer retention, and two are potentially new determinants to enhance the explanation of retention.

\section{Motives for volunteer retention}

Motives for volunteer retention can vary widely across studies. Nonetheless, some studies seem broadly applicable. Lie and Baines (2007) suggest the key motives for volunteers shows similar as: being useful members of society; helping others; putting something back into the community; meeting new people; and pursuing learning and personal development. Grouping these factors suggests a three-level ranking: altruism; social; and personal development. Such a ranking, while appealing, is not yet fully examined in a single quantitative study.

Different nonprofit industries often generate slightly different rankings. In a hospital setting, the three major clusters ranking differ, with more emphasis on self-development over altruism. For example, the Ferreira et al. (2015) Portuguese hospital study ranked personal development as the most important motivator; with altruism (helping others) next; and social (social interaction; forming friendships; meeting people) third. Similar ranking appears in an Irish health care study (MacNeela, 2008). Sometimes the results can be extremely idiosyncratic, specific to a particular nonprofit organization or a particular industry. In Scottish charity retailing, quality of friendships is the dominant motive for volunteer retention (Broadbridge \& Horne, 1994).

The lack of agreement about a broadly general understanding of the rankings of the motives for volunteer retention leads into the second research question for the study: 
RQ2: How can studies provide a more generalizable and comprehensive ranking of the motives for volunteer retention?

\section{Volunteer lifecycle}

The volunteer lifecycle starts from awareness about volunteering, to recruitment, to activation, to building commitment to the organization, retention, and to eventual exit. For some volunteers exit may occur at an early stage due to voluntary or involuntary reasons. Wilson (2012) suggests that volunteer recruitment has received most attention and volunteer retention the least, the latter being the focus of the current paper. Bussell and Forbes (2003) have formalized the volunteer lifecycle to allow for the influences of different stakeholders and for different temporal factors. Their subsequent paper (Bussell \& Forbes, 2006) adapts the model to a relationship marketing framework. A limitation of the Bussell and Forbes work $(2003,2006)$ is that it is essentially theoretical. Not many studies have given empirical understanding to the lifecycle concept, which takes the literature review to the next section.

\section{Changing retention motives over the volunteer lifecycle}

Early pioneers, Starnes and Wymer (2001), building on Fischer and Schaffer (1993), provide an interesting perspective to the volunteer lifecycle, by contrasting different phases of the lifecycle as different emotional states of the relationship between the organization and the volunteer. The initial, short-term phase is described as a "honeymoon" period, which later develops into a more committed relationship of the volunteer with the organization in the longer term 
The two major active phases of the volunteer lifecycle, portrayed by Fischer and Schaffer (1993), provide a useful start. One example of further treatment of the active phases is Haski-Leventhal and Bargal (2008) who present three active volunteer lifecycle phases. On one hand, they develop three active phases, but do so in an atypical context, one that limits generalization. Their analysis using the nonprofit Youth in Distress case suggests three short-lived phases of newcomer, emotional involvement and established volunteer associated with low, high and low commitment respectively. Phase one contrasts with Fischer and Schaffer (1993) honeymoon period. The uncertainty of the role in the newcomer phase in the Haski-Leventhal and Bargal (2008) might relate to the complex and challenging task of newcomers to fit into a demanding situation. Even their relatively blissful and achieving middle phase of emotional involvement entails fluctuations of "ups and downs", deep sadness and high satisfaction. Their third and final active phase of established volunteering is negative, including fatigue and burnout, quickly followed by retirement. Again, their final active phase contrasts with Fischer and Schaffer (1993) where the final years are associated with high commitment.

Haski-Leventhal and Bargal (2008) provide an excellent, deep analysis of the full range of volunteer emotions, activities and considerations of volunteers during each phase, which in turn shapes their choice between progressing to the next phase or exit. The richness of the HaskiLeventhal and Bargal (2008) results stems from its qualitative nature. Lack of detailed empirical studies of the various active phases of the volunteer lifecycle lead the current authors to their third research question, namely:

RQ3: How can researchers clarify and resolve the issue of whether volunteer retention motives change over the volunteer lifecycle? 
Although there seem to be few detailed empirical studies on the active phases of the volunteer lifecycle, there nonetheless seems to be a broad consensus that the motives for continuing as a volunteer can differ significantly from the reasons for having volunteered in the first place. Specifically, the consensus suggests that altruism motives will become less important after the initial recruitment (Bennett \& Barkensjo, 2005; Bussell \& Forbes, 2006; Galindo-Kuhn \& Guzley, 2002; MacNeela 2008; Starnes \& Wymer, 2000; 2001). To test this supposition, the paper develops the following null hypothesis:

H5: That the altruism motive for volunteer retention does not change over the volunteer lifecycle.

This survey of the literature identifies several gaps in the overall understanding of volunteer retention and guides the formulation of the three research questions and the five null hypotheses.

\section{Methodology}

The nature of the research questions requires a quantitative approach to data collection and analysis. A sampling frame initially begins with the choice between a narrow, homogenous organizational unit and a set of diverse, heterogeneous, organizations. Most studies in the nonprofit domain are narrow in scope, either single industry or organization, such as volunteers in hospitals. Some studies have more diverse sampling, including Hulbert and Chase (1991), and Willems and Drury (2017). The current study requires a more diverse set of nonprofit organizations. All three research questions seek more generalizable answers to fundamental behaviours. Research Question 2 in particular has been proposed to overcome the idiosyncrasies of single industry 
studies. For example, retail volunteers emphasize friendship as the major motive for retention (Broadbridge \& Horne, 1994) while hospital volunteers emphasize personal skill development (maybe to later access to a paid job) (Ferreira et al., 2015; MacNeela, 2008). None of these studies is generalizable, leading to the need for more diverse sampling. Similarly, one of the few studies empirically examining changing retention motives over the volunteer lifecycle is Haski-Leventhal and Bargel (2008). The single industry study of difficult to handle children with criminal histories most likely contributes to burnout and the noted swings in retention motivation, not appropriate for empirical generalizations.

To guide and structure the sampling selection, three sequential criteria apply. Firstly, only Australian, nonprofit, service organizations are included, as a means of giving a specific service industry focus to the study. Secondly, the population frame was further restricted to organizations that were publically identified by winning or being nominated for various awards, such as for effective organization change. Thirdly, the researchers approached the identified nonprofit organizations to request their participation in the study. Applying these criteria gave fourteen Australian nonprofit organizations that agreed to participate. All participating organizations were nonprofit in character. By heterogeneous design, the scope of their activities varies widely. Services covered included community mental health, health, disability, disability support, community networks, museum, amateur performing arts and community radio.

Recruitment of respondents (individual volunteers) from within each of the fourteen organizations proceeded as follows. Direct access to volunteer personnel details was not appropriate. That is, it was inappropriate for the researchers to obtain what would be confidential data about volunteers 
from the organization. Rather, the researchers used the organization's management as the conduit to collect information from volunteers. To optimize management involvement in the process, care was given to explaining the purpose of the proposed study and the potential benefits to the organization. Once the organizations agreed to allow their volunteers to participate in the study, then their volunteers were invited to participate. The researchers provided assurance to the volunteers about the confidentiality of their responses, with the responses sent directly to the researchers.

The structured survey uses 5-point Likert scales (anchored at 1 for strongly agree and 5 for strongly disagree). The structured survey included items relating to motives for retention based on a list of ten motives. Further questions related to the following multi-item concepts, with the data sources indicated in parentheses: volunteer work satisfaction (sources: Bennett \& Barkensjo, 2005; Jensen \& McKeage, 2015); volunteer organizational commitment (sources: Bennett \& Barkensjo, 2005; Jensen \& McKeage, 2015; Merrilees et al., 2017); intention to continue volunteering (source: Bennett \& Barkensjo, 2005; Jensen \& McKeage, 2015; Merrilees et al., 2018), and valuescongruency (sources: Locke et al., 2003; Merrilees et al., 2017; Randle \&, 2011; Smith \& Cordery, 2010). Further, a new three-item altruism construct is developed in this paper, based on exploratory factor analysis, which is summarized in the preliminary results section. The age demographic variable was collected for use as a control variable in the regression analysis. However, it was removed after being very small in magnitude and statistically insignificant. Length of tenure was collected and used as a moderating variable in Tables 3 and 4. 
Finally, the survey instrument includes a small though important qualitative section, comprising two open-ended questions, complementing the quantitative analysis. Firstly, the respondent rates on a five-point Likert scale, each of ten listed factors that motivate that volunteer to stay with the organization, and immediately after, an open-ended question asks: "Which ONE of the ABOVE MOTIVATORS has INCREASED in importance since you joined the organization? Please specify here: empty box given". The rationale for this question is to understand how the motives for staying might change over volunteer life cycle, since initial recruitment. This approach seems to pioneer the asking of such a question of volunteers. Emphasis was given to the single most important change, as a top-of-mind question, to facilitate information processing in the head of the volunteer. The attraction of this question is that it provides a third method of assessing changing motives over the volunteer lifecycle. The qualitative responses are a quasi-type of longitudinal picture of how important motives emerge, directly expressed by the volunteer. The coding of the answers corresponded closely with one of the ten, survey instrument aforementioned motives, with the volunteer either mentioning the number of the motive or paraphrasing a particular motive.

A second open-ended qualitative question asks respondents to note "What factors are special about volunteering for this organization?" The rationale of this question was to seek out, in an unconstrained way, how the volunteer really connects with the organization. Top-of-the-mind answers are likely to be forthcoming. The responses were usually closely allied to one or more the ten listed motivators, even though the wording of the particular open-ended question clearly makes no explicit reference to the motivators. The close connection of the answers to one or more (combinations of) motivators, but expressed in the words of the respondent, facilitated the coding of the answers. Thus, the answer for one respondent to the question of what was special about 
volunteering for this organization was "I love being part of the community and giving a helping hand", which coincides with two of the ten motivators and indeed two of the three facets of altruism as newly defined in this paper. The attraction of this question is that it enables more texture and nuance to the motivating concept as it is in the voice of the volunteer. Hence, a special attraction is the support for the three-facet altruism concept because many of the answers combine two or three facets in a seamless, holistic way, without direction from the interviewer.

The volunteer respondents answered using the self-administered structured survey, which was available either online or in hard copy, contingent on the organization. Lin and Van Ryzin (2012) argue that there is little difference in the characteristics of respondents using either response mode. Four organizations used the print surveys together with an online survey with comparable format; two organizations used print only; and eight used online only. After data cleaning there were 357 usable responses.

Preliminary data analysis was conducted to demonstrate that the sample was broadly representative of the nonprofit sector. That section also includes exploratory factor analysis of the ten retention motives to ascertain whether there are multi-item scales within the set. In anticipation, only one multi-item grouping of motives emerges, namely a three-item altruism scale. Reliability of scales was tested using a Cronbach Alpha test. Three methods of validity testing are applied: criterion validity (Average Variance Extracted), discriminant validity and construct validity. The main data analysis uses multiple regression analysis. Intention to stay with the organization is the dependent variable. There are four independent variables, allied to $\mathrm{H} 1$ to $\mathrm{H} 4$. Multiple regression analysis is particularly effective as a co-variance method explaining the variance of intention to stay, which 
is the purpose of RQ1. Multiple regression analysis is also applied at a disaggregated level, by length of tenure, to explain how the determinants vary across the volunteer lifecycle. Such disaggregation enables assessment of whether the altruism motive varies across the lifecycle, which one of three methods of evaluating RQ3 and H5 in particular. A second method of evaluating RQ3 entailed testing for the statistical significance of the ten motivational factors across the phases of the lifecycle. A third method of evaluating RQ3 required coding and enumerating the responses to the first open-ended question. RQ2 simply required calculating the average score for the ten motivations to stay in the organization.

\section{Results}

The results are divided into preliminary results; a multiple regression model of volunteer retention; an analysis of volunteer motives for retention; and an analysis of patterns of retention motives across the volunteer lifecycle.

\section{Results: Preliminary}

The preliminary results indicate that a reasonable representation is achieved by the sampling. The median duration of volunteering is 2.1 years, with 31 percent of the sample serving 5 or more years and 13 percent 10 or more years. About 29 percent of the sample has one year of service. The tenure data splits into four roughly equal nominal groups: (1) tenure 1 year, with 106 respondents; (2) tenure 2 years, with 71 respondents; (3) tenure 3 and 4 years, with 71 respondents; (4) tenure 5 years and more, with 109 respondents. Considerable use will be made of these groupings, which feature in Tables 3 and 4 and form the textured basis of the volunteer lifecycle pattern. The respondent numbers by age group are: 61 (18-24 yrs.), 59 (25-34 yrs.), 41 (35-44 yrs.), 73 (45-54 
yrs.), 74 (55-64 yrs.), 33 (65-69 yrs.), 11 (70-74 yrs.), and 5 (75 yrs. plus). Women predominate at 77 percent of the sample, reflecting a female-centric volunteering population.

Exploratory factor analysis of the ten retention motivations examined whether any multi-item scales emerged. Only one such factor emerged, namely a three-item altruism factor covering the cause, community service and helping others. Using a person's expertise did not combine with wanting to develop expertise, thus two different motives. Similarly, seeking friendships from other volunteers did not combine with seeking friendships from the public, again two different motives. All five scales have good Cronbach Alpha scores, ranging from 0.86 to 0.93 (see Table 1). Each score meets the threshold guideline of 0.70 for having a reliable scale (Nunnally and Bernstein, 1994). Similarly, all scales have satisfactorily high factor loadings, concluding that the scales are meaningful and reliable. Several tests examined the validity of the scales. Firstly, criterion validity was met by having all AVEs greater than 0.50 . Secondly, discriminant validity was met by meeting the Fornell and Larcker (1981) test of the square root of the scale AVE greater than the intercorrelation of that construct with all other constructs. Thirdly, construct validity was achieved based on confirmatory factor analysis. The measurement model showed a good fit with the data (Chi-square 37.9; GFI=0.99; RMSEA=0.038; Bollen-Stine $\mathrm{p}=0.248$ ).

\section{Results pertaining to RQ1: Empirical model of volunteer retention}

Research Question One addresses the need to better explain the variance in volunteer intention to stay in the organization. Four hypotheses structure the process. In Table 1, the second column refers to what is called the fundamental model (model 1) of volunteer retention, where the two explanatory variables are work satisfaction and organizational commitment. The demographic 
variable age was initially included as a control variable, but later removed after it had a very small coefficient and was statistically insignificant. As shown in Table 1, a reasonably high level of explanation is achieved, with the adjusted R-square of 0.42 , significant at the one percent F-value. There is also no evidence of a multicollinearity problem with Variance Inflation Factor (VIF) less than 2. Based on these overall indicators, confidence can be placed in the results allowing focus on the testing of the hypotheses. The Model 1 results rejects the null hypotheses 1 and 2, $(\mathrm{H} 1, \mathrm{H} 2)$ supporting a strong contribution of both volunteer work satisfaction and volunteer commitment to the organization to explaining the variance in volunteer retention.

Model 2 in Table 1 adds values-congruency as a potential antecedent of volunteer retention. The results reject the null hypothesis $3(\mathrm{H} 3)$, supporting the additional contribution of valuescongruency to explaining the variance in volunteer retention. Model 3 in Table 1 adds altruism motivation as a potential antecedent of volunteer retention. The results reject the null hypothesis 4 (H4), supporting the additional contribution of altruism motivation to explaining the variance in volunteer retention.

In summary, the results support an expanded model of volunteer retention. Consistent with previous studies in the nonprofit literature (Bennett \& Barkensjo, 2005; Jensen \& McKeage, 2015), work satisfaction and work commitment are two important determinants of volunteer continuance. Both determinants have sizeable coefficients that are statistically significant at the one per cent level. Two variables, values-congruency and altruism motivation are added to the fundamental model to provide a more comprehensive explanation of volunteer retention. 
Results pertaining to RQ2: Toward a more generalizable and comprehensive ranking of the motives for volunteer retention?

Table 2 ranks the ten motives for volunteer continuing to stay in the nonprofit organization. The table gives the top three motives to remain volunteering with the current organization as: (1) the purpose/cause of the nonprofit organization; (2) giving service to the community and (3) compassion in helping. Explanatory factor analysis in the Preliminary Results section indicates that these three motives combine into a multi-faceted altruism construct. Number 2-ranked, compassion in helping others, is commonly noted very strongly in the literature. Number 3-ranked, giving service to the community, is often highly ranked, though not always as a top three entry. Number 1-ranked, having a great cause, is perhaps the major surprise, partly because it is not usually even considered in ranking studies. The authors have only been able to decipher two studies including cause as an explicit motive. Starnes and Wymer (2000) found "believe in the hospice mission" the number one retention motive in their study, while Hulbert and Chase (1991) found that "worthwhile cause" was identified as the main single reason for volunteering.

Number 5-ranked, meeting with interesting members of the public/clients ranks a strong middle position in Table 2, a relatively stronger position compared to most other studies (e.g. Karl et al., 2008; MacNeela, 2008). A number of respondents noted that they enjoyed the opportunity to meet people with similar issues to themselves or their relatives. Developing skills was ranked poorly (ninth), though the literature review suggests that in some sectors, like hospitals, a stronger ranking might apply. Adding to the veracity of the results is the bottom ranking, financial benefits. Compared to paid staff, and reflecting the nature of volunteering, volunteers are not strongly motivated by financial benefits, giving credence to the last-placed ranking of financial benefits. 


\section{Results pertaining to RQ3: Do volunteer retention motives change over the volunteer lifecycle?}

The literature review highlights that volunteer motives may change over the volunteer lifecycle. Three sets of results in this paper suggest a different picture. Firstly, examining a matrix of the ten motives as rows and the four levels of volunteer tenure (defined in Table 3) as columns, it was possible to statistically test whether the motive ratings varied by tenure. All changes were numerically very small. In only two cases (using expertise and developing skills) was the small difference statistically significant, indicating a high level of stability of motivations across the volunteer lifecycle. For each motive, there were small increases in rating, especially going from 2 years to 3-4 years, but usually it was not significant. These quantitative tests suggest a high level of stability of volunteer motives over the lifecycle. Secondly, referring to Table 3, the four multiple regression models relate to each level of tenure; from one year of tenure, to two years of tenure, to 3 and 4 years of tenure; and to five and more years of tenure. For the first two of four phases of the active volunteer lifecycle, work satisfaction and organizational commitment are the primary determinants of intention to volunteer. Altruistic motivation plays a supportive, but much lesser role. However, for the last two phases of the lifecycle, altruistic motivation plays a major role, with a beta coefficient of 0.32 and 0.40 respectively in the last two phases. From volunteer tenure year three onwards, altruistic motivation becomes the dominant factor influencing the intention of volunteers to continue volunteering. This second set of results again supports the notion that the altruistic motive does not diminish over the lifecycle.

Thirdly, Table 4 enumerates answers by respondents to the open-ended question of identifying whether a particular motive has increased in importance since their recruitment. For about 30 
percent of the respondents there was no change in motives indicated, which is a noteworthy statistic in itself. For those who did nominate a motive increasing in importance, the dominant motive came from the top three, representing altruism. The only other mentions of any note were meeting with interesting members of the public/clients (46 respondents) and "the work allows me to develop my skills" (24 respondents). Note that the data is qualitative and suggestive of changes on a quasilongitudinal (reflective) basis. Only four of the ten motives show a noticeable change, but do seem to indicate that the altruistic motivation are not declining and may be increasing over the volunteer lifecycle.

Overall, the three set of results pertaining to RQ3 provide useful perspectives of how and the extent of change in retention motives over the volunteer lifecycle. The over-riding conclusion is that volunteer retention motives do not change substantially over the four volunteer lifecycle phases following recruitment. In particular, the results indicate that the null Hypothesis 5 (H5) cannot be rejected for the first set of results. For the second and third set of results pertaining to RQ3, the results actually suggest that the altruism motive for retention might become more important over the lifecycle.

\section{Discussion}

The discussion divides into three categories: motives for volunteer retention; changes of volunteer motives over the volunteer lifecycle; and the overall concept of the volunteer lifecycle.

\section{Motives for volunteer retention}


A limitation of some previous studies of motives for volunteer retention is that they may be restricted to a particular industry or organization. However, broader contexts are needed to discover a more generalizable ranking of motives. The current study covers fourteen non-profit organizations across diverse sectors and has the potential to ascertain a more generalizable ranking of motives.

The results, shown in Table 2 and detailed in the Results section, are broadly self-explanatory. What requires discussion is the overwhelming importance of the altruism motive, which occupies the top three positions in Table 2, namely being compassionate about people in need; giving service to the community; and identifying with the great cause (purpose) of the organization. Each of these reflects a particular facet of altruism, forming a new combined concept generated by exploratory factor analysis in this study. The first facet of altruism, being compassionate about helping people in need, is perhaps the ultimate expression of altruism. However, giving service to the community is essentially a macro counterpart of the compassionate motive. Both facets seem essential for altruism and are sometimes expressed as a combination in other studies, for example, "a community orientation to help others" (Taghian et al., 2012). Thus, the general notion is helping others and giving back to society. The third facet of altruism, namely the specific cause or purpose of an organization, is included in the newly defined three-item altruism concept. Different volunteers will be orientated and attracted to different non-profit organizations precisely because of their affinity to a particular cause or purpose. Interestingly, the "specific cause" has rarely featured in previous rankings of retention determinants, with two notable exceptions, namely Hulbert and Chase (1991) and Starnes and Wymer (2000). The present study advocates that it is 
useful to include the specific cause as a third facet of altruism because the cause focuses, mediates and manifests attention to operationalize the compassion and service.

Including the cause as a third facet of altruism provides a partial answer to Smith's (1981) paradox that altruism is not absolute, but relative. That is, they argue, volunteers cannot act solely altruistically, but are also motivated by other rewards. Thus, identifying a particular cause adds some specificity to the value of altruism. Helping others is channelled into a particular stream by the specific nonprofit mission. All three facets seem useful to define the scope of the altruistic motive. Overwhelmingly, the altruistic motive is a dominant force influencing volunteer retention (Table 2). In the words of some respondents elaborating on their special regard to their organization (the second open-ended question presented in the Methodology section):

"The compassion to help people in need and giving service to the community".

"The opportunity to be part of a great organization"

"Being part of the community"

"I love being part of the community and giving a helping hand"

"Sense of community and common purpose"

"The mission of the organization and the impact it has on the community"

"There is real compassion to help people in need".

The selective expressions of the volunteers impinging of the altruism motive suggest that many respondents are able to articulate in their own words a meaning for altruism that reinforces and sometimes combines some of the facets.

\section{Changes of volunteer motives over the volunteer lifecycle}


Numerous studies allude to the motives for retention potentially differing from the initial motives for volunteers to join a non-profit organization. Overwhelmingly, the literature suggests that a possible dominant motive of altruism at the recruitment phase, may shift to more egoistic motives (such as personal development) being relevant for volunteer retention. For about 30 percent of the sample, there is no change in the pattern of motives over the lifecycle. However, contrary to the majority of the literature, there is no evidence that the altruism motive diminishes over the volunteer lifecycle. What seems to be happening is that the "meaning" of altruism intensifies in Phases 3 and 4 of the volunteer lifecycle (see Tables 3 and 4).

The novelty and unexpected nature of this finding will require qualitative research to discern a robust explanation. As a tentative line of explanation, perhaps through their longer experiences within a specific organization in a specific community context, mature volunteers may internalize that clients derive immense benefits (help) from the nonprofit mission. Perhaps it is this greater understanding of the cause-service-compassion nexus that contributes to the altruism related bond to stay (retention) over the lifecycle that is revealed in Tables 3 and 4. Future qualitative research could potentially throw more light on this newly discovered phenomenon.

\section{Volunteer lifecycle}

Finally, the current study makes several inroads to better understanding the volunteer lifecycle. Most importantly, the study contributes to greater insight into the volunteer retention decision, which Wilson (2012) argues is the most neglected part of the volunteer lifecycle. Apart from advancing the statistical model explaining retention, the study also progresses clarity into the motives underpinning volunteer retention. Using the four levels of volunteer tenure (shown in 
Tables 3 and 4) adds texture and practicality to the volunteer lifecycle. Other countries and studies may come up with slightly different time-periods for each phase and there will always be individual volunteer differences. However, tentatively, the results suggest the following four temporal phases:

Phase 1: Volunteer Tenure 1 year (Honeymoon Relationship). The initial phase following recruitment seems to be about 6 to 12 months in duration and corresponds to what Starnes and Wymer (2001) and Fischer and Schafer (1993) refer to as a honeymoon period of the relationship of the volunteer with the non-profit organization. Commitment levels are at a medium level and both parties to the relationship are still learning about each other. There is a certain faith that everything will turn out acceptably, but the substance of the relationship is not fully formed.

Phase 2: Volunteer Tenure 2 years (Post-Honeymoon Blues Relationship). To some extent, at first glance, the second year seems a continuation of the honeymoon period. Commitment levels are little changed. However, in some areas there is a sense that change is in the air and it could go either way: up (greater commitment) or down (exit). It is a type of transition or disjunction. Fischer and Schaffer (1993) in fact suggest that even in the short-term, "the honeymoon" stage of euphoria may regress to a "post honeymoon blues" phase after volunteers gain experience. The evidence in the current study suggests that year one is the "honeymoon" phase while year 2 of volunteering is the "post honeymoon blues" phase. There are two sets of data to support the onset of a "post honeymoon blues" phase. Firstly, of the four volunteer tenure phases, the ten retention motives are at their weakest level during this time. Further, the Table 3 regression sub-models reveal the 
various tensions, partly by comparing Phase 1 to Phase 2, but especially in comparing Phases 2 and 3. The altruism motive beta-coefficient, in particular, is the weakest in Phase 2.

Phase 3: Volunteer Tenure $3 \& 4$ years (Consolidated Relationship). After 3 or 4 years, the relationship has matured into a medium-term relationship which is defined here as the Consolidated Relationship Phase of the volunteer lifecycle. Both parties more or less understand each other. Volunteers are clearly committed to the organization. Notwithstanding, some exceptions exist and there will still be some volunteers exiting for various reasons. The altruism motive acts as a major force stimulating the volunteer to continue (see Table 3 beta coefficient of $0.32)$.

Phase 4: Volunteer Tenure 5 \& more years (Deep Commitment Relationship). After five years, the relationship has further matured into a long-term relationship, which is defined here as the Deep Commitment Phase of the volunteer lifecycle. As noted in the preliminary results, 31 percent of the current sample fit into this category, nearly half of which have served ten or more years. During this fourth phase, the close bond between the two parties may lead to more forgiveness if things go wrong (Bennett \& Barkensjo, 2005). The altruism motive again acts as a major force stimulating the volunteer to continue (see Table 3 beta coefficient of 0.40 ).

Overall, the study provides a further platform for both future academic research and for practical application in the contemporary nonprofit context. 


\section{Implications for Nonprofit Management}

Maintaining high levels of volunteer retention is a primary objective of nonprofit management. The findings can be put into practice, starting with the statistical model in this paper comprising four antecedent variables, all of which have a strong influence on the volunteer retention decision. Two of the variables, a volunteer's commitment to the nonprofit organization, and volunteer work satisfaction, are critical relationship marketing variables, which can be stimulated with appropriate supportive management policies and programs. The results emphasizing volunteer satisfaction and commitment fit with the existing literature, and suggest a range of possible management measures. However, different nonprofit organizations will be in various states of readiness. For nonprofit organizations with low-level marketing capability, they need to develop a shared sense about the organization between managers, volunteers and other groups (Pope et al., 2009). Nonprofits with advanced capabilities can consider using transformational leadership and branding to build stronger relationships with volunteers. The use of transformational leadership is emphasized in a Barnardos' case study by Devaney et al. (2015), and more generally by Ockenden and Hutin (2008). Branding is a further means of building better relationships with volunteers (Hankinson \& Lomax, 2006; Sullivan Mort et al., 2007). An insightful Australian example is the disability services nonprofit Connect2Group, which develops a strong brand based on integrating empowered workers and empowered clients (Miller \& Merrilees, 2013).

With average levels of nonprofit management capability, use can be made of basic human resource management (HRM) practices to manage volunteers. Cuskelly et al. (2006) demonstrate that basic nonprofit management HRM skills in planning, recruitment, orientation, training, support, performance management and recognition can help alleviate volunteer retention problems, and 
could be used across all four of the volunteer lifecycle phases. However, while a basic set of HRM practices can help, they have been deemed insufficient to build closer relationships with volunteers (Studer \& von Schnurbein, 2013). More relationship management measures are needed to bridge the gap between what organizations offer and what volunteers need. To help understand better how relationship marketing techniques can help build enhanced relationships with volunteers, use can be made of the other major finding of the current study, namely the identification of a four phase volunteer lifecycle.

Phase 1 of the volunteer lifecycle (Honeymoon Relationship) applies to the first year of appointment as a volunteer and has been described by Starnes and Wymer (2001) and Fischer and Schafer (1993) as a "honeymoon period". The initial euphoria may make it seem that all is well, when it may not necessarily be. Active relationship management is called for, particularly a socialization program that embeds the volunteer into the organization to enure that mutual needs are being met in the context of that organization (Bussell \& Forbes, 2006; Haski-Leventhal \& Bargal, 2008; Reamon, 2006). Adequate volunteer support is needed in all phases (Bennett \& Barkensjo, 2005; Warburton et al., 2013). Phase 2 of the volunteer lifecycle (Post Honeymoon Blues Relationship) is tentatively designated as year 2 of the volunteer tenure with an organization. Superficially, everything may seem acceptable and commitment levels moderately high. However, the notion of "post honeymoon blues" may set in (see Fischer \& Schafer, 1993). At this point, it may be necessary for nonprofit organizations to customize the socialization process so that individual volunteer needs are being addressed in fulfilling ways. The need for more flexibility across the Volunteer Life Cycle is also highlighted by Bussell and Forbes (2006). 
Phase 3 of the volunteer lifecycle (Consolidated Relationship) is tentatively designated as years 3 and 4 of the volunteer tenure with an organization. There will be fewer issues with this group, but it is still important to understand whether volunteer needs have evolved and to address any changes. A special need is to ensure that both parties more deeply connect to the cause/purpose (mission) of the nonprofit organization. Phase 4 of the volunteer lifecycle (Deep Committed Relationship) is tentatively designated as five years and more of the volunteer tenure with an organization. As with the previous group, there will be few issues, but still a responsibility to address changing needs, if any. There is also the same special need to ensure that both parties more deeply connect to the cause/purpose (mission) of the nonprofit organization. Perhaps the Deep Committed Relationship group, more than other groups, could be allocated leadership/supervisory roles to tap their accumulated wisdom and experience. One of the four key variables in the volunteer retention model in Table 3 is values-congruency, consistent with previous literature (Locke et al., 2003; Randle \& Dolnicar, 2011; Smith \& Cordery, 2010). Such a variable is not a pure management variable, nor a pure volunteer variable. It is more the fit of values between the two entities, which can be fostered by management. In some cases, alignment of identity is essential to a nonprofit organization, with Brandt (1998) demonstrating that Girl Scout Leader retention can be increased when the Leader's self-image merged with the role. In contrast, an extra challenge to managing volunteers in the Australian Meals on Wheels program is the divergence of values, with older volunteers actively resisting change to new policy directions (Warburton et al., 2018). 
Overall, there are many practical opportunities for nonprofit organization managers to work with volunteers throughout the lifecycle for mutual benefit, and to support the cause or purpose of the organization.

\section{Limitations}

Although every effort has been made to achieve a broad-based, diverse sample of non-profit organizations, a different selection may have given slightly different results. Thus, additional studies are needed to reinforce the thrust of the current paper. Further, as per generalized models in other marketing contexts, such as SERVQUAL (Parasuraman et al., 1988), subsequent studies of individual industries or organizations may deviate from the general pattern for idiosyncratic reasons. For example, retail volunteers may place greater emphasis on friendships as a motive to stay. Nonprofit organizations need to be alert to such idiosyncrasies. Further, the sampling selection criteria give confidence that all of the selected fourteen organizations are in the average to best practice range, rather than bad practices. Some of the awards are just nominations rather than winning; and some are more narrowly for merely improving practices, so not all fourteen selections will be whole-of-organization best practices. Excluding bad practice non-profit organizations gives confidence that the results are not distorted from such firms. Notwithstanding, poorly performing non-profit organizations are likely to experience additional challenges regards volunteer retention. Finally, the paper focuses on one aspect of the volunteer life cycle, namely volunteer retention. Other studies are required to address the initial decision to volunteer (Willems \& Dury, 2017) and the decision to quit rather than remain in the organization (Willems et al., 2012). 


\section{Conclusions}

The volunteer life cycle is a promising concept for understanding and enhancing volunteer retention. This empirical study contributes a further perspective on the retention component of the lifecycle. Five major developments are advanced in the paper. Firstly, the prevailing quantitative model of volunteer retention emphasizing commitment and satisfaction is extended to include values-congruency and volunteer motives. Secondly, a more general, broad-based ranking is provided on volunteer retention motives, where altruism emerges as the major element. Thirdly, a new three-item perspective of altruism, based on helping; service; and the non-profit cause or purpose, is formulated and tested. Fourthly, in contrast to the literature, there appears to be no lessoning of the altruism retention motive over the lifecycle. Fifthly, some texture and nuances are

given to the volunteer lifecycle, with four chronological phases proposed, named as: Phase 1 of the volunteer lifecycle (Honeymoon Relationship); Phase 2 of the volunteer lifecycle (Post Honeymoon Blues Relationship); Phase 3 of the volunteer lifecycle (Consolidated Relationship); Phase 4 of the volunteer lifecycle (Deep Committed Relationship). Future research can address the veracity of these five major findings and especially focus and elaborate on variations of volunteer behaviour across the four proposed phases of the active volunteer lifecycle.

\section{Disclosure statement}

The authors reported no potential conflict of interest. 


\section{References}

ABS (Australian Bureau of Statistics) (2014). Volunteering. General Social Survey: Summary Results, Australia, 2014. Catalogue No. 4159.0. Retrieved from http://www.abs.gov.au/ausstats/abs@.nsf/Latestproducts/4159.0Main\%20Features152014 ?opendocument $\&$ tabname $=$ Summary $\&$ prodno=4159.0\&issue $=2014 \&$ num $=\& v i e w=$

Bennett, R., \& Barkensjo, A. (2005). Internal marketing, negative experiences, and volunteers' commitment to providing high-quality services in a UK help and caring charitable organization. Voluntas: International Journal of Voluntary and Nonprofit Organizations, 16(3), 251-274.

Bennett, R., \& Kottasz, R. (2001). Advertisement style and the recruitment of charity volunteers. Journal of Nonprofit and Public Sector Marketing, 8 (2), 45-63.

Brandt, L. (1998). Girl Scout Volunteer Leader Retention: An Issue of Self-Role Merger. South Dakota State University.

Broadbridge, A., \& Horne, S. (1994). Who volunteers for charity retailing and why. Service Industries Journal, 14(4), 421-437.

Bussell, H., \& Forbes, D. (2003). The volunteer life cycle: a marketing model for volunteering. Voluntary Action, 5(6), 61-79.

Bussell, H., \& Forbes, D. (2006). Developing relationship marketing in the voluntary sector. Journal of Nonprofit \&Public Sector Marketing, 15(1-2), 151-174.

Clary, E. G., Snyder, M., Ridge, R., Copeland, J., Stukas, A., Haugen, J., \& Miene, P. (1998). Understanding and assessing the motivations of volunteers: A functional approach. Journal of Personality and Social Psychology, 74(6), 1516-1530.

Cnaan, M., \& Amrofell, L. (1994). Mapping volunteer activity. Nonprofit and Voluntary Sector Quarterly, 23(4), 335-351.

Cuskelly, G., Taylor, T., Hoye, R., \& Darcy, S. (2006). Volunteer management practices and volunteer retention: A human resource management approach. Sport Management Review, 9(2), 141-163.

Devaney, C., Kearns, N., Fives, A., Canavan, J., Lyons, R., \& Eaton, P. (2015). Recruiting and retaining older adult volunteers: Implications for practice. Journal of Nonprofit \& Public Sector Marketing, 27(4), 331-350. 
Ferreira, M. R., Proença, T., \& Proença, J. F. (2015). Volunteering for a lifetime? Volunteers' intention to stay for Portuguese hospitals. VOLUNTAS: International Journal of Voluntary and Nonprofit Organizations, 26(3), 890-912.

Fischer, L. R., \& Schaffer, K. B. (1993). Older Volunteers: A Guide to Research and Practice. Newbury Park: SAGE Publications.

Fornell, C., \& Larcker, D. F. (1981). Evaluating structural equation models with unobservable variables and measurement error. Journal of Marketing Research, XVIII(1), 39-50.

Galindo-Kuhn, R., \& Guzley, R. M. (2002). The volunteer satisfaction index: Construct definition, measurement, development, and validation. Journal of Social Service Research, 28(1), 45-68.

Hankinson, P., \& Lomax, W. (2006). The effects of re-branding large UK charities on staff knowledge, attitudes and behaviour. International Journal of Nonprofit and Voluntary Sector Marketing, 11(3), 193-207.

Haski-Leventhal, D., \& Bargal, D. (2008). The volunteer stages and transitions model: Organizational socialization of volunteers. Human Relations, 61, 67-102.

Haski-Leventhal, D., Hustinx, L., \& Handy, F. (2011). What money cannot buy: The distinctive and multidimensional impact of volunteers. Journal of Community Practice, 19 (2), 138158.

Hulbert, J. R., \& Chase, R. A. (1991). Retiree Volunteers and the Agencies They Serve: A National Survey. May 1991, Final Report. Sponsored by the National Retiree Volunteer Center. Wilder Research Center, St Paul MN.

Jensen, K., \& McKeage, K. (2015). Fostering volunteer satisfaction. Journal of Nonprofit Education and Leadership, 5(3), 174-189.

Karl, K. A., Peluchette, J. V., \& Hall, L. M. (2008). Give them something to smile about: A marketing strategy for recruiting and retaining volunteers. Journal of Nonprofit \& Public Sector Marketing, 20(1), 71-96.

Lie, M., \& Baines, S. (2007). Making sense of organizational change: Voices of older volunteers. Voluntas: International Journal of Voluntary and Nonprofit Organizations, 18(3), 225240. 
Lin, W., \& Van Ryzin, G. (2012). Web and mail surveys: An experimental comparison of methods for nonprofit research. Nonprofit and Voluntary Sector Quarterly, 41(6), 1014-1028.

Locke, M., Ellis, A., \& Smith, J. (2003). Hold on to what you've got: The volunteer retention literature. Voluntary Action, 5(3), 81-99.

MacNeela, P. (2008). The give and take of volunteering: Motives, benefits, and personal connections among Irish volunteers. VOLUNTAS: International Journal of Voluntary and Nonprofit Organizations, 19(2), 125-139.

Merrilees, B., Miller, D., Ge, G., \& Tam, C. C. C. (2018). Asian city brand meaning: A Hong Kong perspective. Journal of Brand Management. 25(1), 14-26.

Merrilees, B., Miller, D., \& Yakimova, R. (2017). The role of staff engagement in facilitating staff-led value co-creation. Journal of Service Management. 28(2), 250-264.

Miller, D., \& Merrilees, B. (2013). Rebuilding community corporate brands: A total stakeholder involvement approach. Journal of Business Research, 66, 172-179.

Nunnally, J. C., \& Bernstein, I. H. (1994). Psychometric Theory. (3 ${ }^{\text {rd }}$ ed.) McGraw-Hill, New York.

Ockenden, N., \& Hutin, M. (2008). Volunteering to Lead: A Study of Leadership in Small, Volunteer-Led Groups. New Zealand Institute for Volunteering Research.

Pope, J. A., Isely, E. S., \& Asamoa-Tutu, F. (2009). Developing a marketing strategy for nonprofit organizations: An exploratory study. Journal of Nonprofit \& Public Sector Marketing, 21(2), 184-201.

Randle, M., \& Dolnicar, S. (2011). Self-congruity and volunteering: A multi-organization comparison. European Journal of Marketing, 45(5), 739-758.

Reamon, S. (2016). Managing volunteers: Recruitment, retention, and relationship building. SPNHA Review, 12(1), 74-95.

Rupp, C., Kern, S., \& Helmig, B. (2014). Segmenting nonprofit stakeholders to enable successful relationship marketing: A review. International Journal of Nonprofit and Voluntary Sector Marketing, 19(2), 76-91.

Smith, D. H. (1981). Altruism, volunteers, and volunteerism. Journal of Voluntary Action Research, 10(1), 21-36.

Smith, K., \& Cordery, C. (2010). What works? A systematic review of research and evaluation literature on encouragement and support of volunteering. Report, Victoria University of 
Wellington, June, 1-36. Retrieved from

https://www.researchgate.net/profile/Carolyn_Cordery/publication/228271688_What_W

orks_A_Systematic_Review_of_Research_and_Evaluation_Literature_on_Encourageme nt_and_Support_of_Volunteering/links/0912f50f5d138e4a01000000.pdf

Starnes, B. J., \& Wymer Jr, W. W. (2000). Demographics, personality traits, roles, motivations, and attrition rates of hospice volunteers. Journal of Nonprofit \& Public Sector Marketing, 7(2), 61-76.

Starnes, B. J., \& Wymer Jr, W. W. (2001). Conceptual foundations and practical guidelines for retaining volunteers who serve in local nonprofit organizations: Part II. Journal of Nonprofit \& Public Sector Marketing, 9(1-2), 97-118.

Studer, S., \& von Schnurbein, G. (2013). Organizational factors affecting volunteers: A literature review on volunteer coordination. VOLUNTAS: International Journal of Voluntary and Nonprofit Organizations, 24(2), 403-440.

Sullivan Mort, G., Weerawardena, J., \& Williamson, B. (2007). Branding in the non-profit context: The case of Surf Life Saving Australia. Australasian Marketing Journal, 15(2), 108-118.

Taghian, M., D'Souza, C., \& Polonsky, M. (2012). A study of older Australians' volunteering and quality of life: Empirical evidence and policy implications. Journal of Nonprofit \& Public Sector Marketing, 24(2), 101-122.

Warburton, J., Moore, M., \& Oppenheimer, M. (2018). Challenges to the Recruitment and Retention of Volunteers in Traditional Nonprofit Organizations: A Case Study of Australian Meals on Wheels. International Journal of Public Administration, 41(16), 1361-1373.

Warburton, J., Smith-Merry, J., \& Michaels, C. (2013). Delivering community services in a new world of volunteering: a case study from Sydney, Australia. International Journal of Public Administration, 36(11), 798-806.

Willems, J., \& Dury, S. 2017. Reasons for not volunteering: Overcoming boundaries to attract volunteers. Service Industries Journal, 37(11-12): 726-745

Willems, J., Huybrechts, G., Jegers, M., Vantilborgh, T., Bidee, J., \& Pepermans, R. 2012. Volunteer decisions (not) to leave: Reasons to quit versus functional motives to stay. Human Relations, 65(7): 883-900. 
Wilson, J. (2012). Volunteerism research: A review essay. Nonprofit and Voluntary Sector Quarterly, 41(2), 176-212.

Wymer, W. Jr, \& Starnes, B. (2001). Conceptual foundations and practical guidelines for recruiting volunteers to serve in local nonprofit organizations: Part 1. Journal of Nonprofit \& Public Sector Marketing, 9(1-2), 63-96. 
Table 1: Multiple Regression Models of Volunteer Continuance Dependent variable: Intention to remain in the nonprofit organization

$$
(\mathbf{n}=357)
$$

\begin{tabular}{lccc}
\hline Antecedents & Model 1 & Model 2 & Model 3 \\
\hline Volunteer Work Satisfaction & 0.40 & 0.36 & 0.29 \\
Organizational Commitment & $(8.87)^{* *}$ & $(7.62)^{* *}$ & $(6.18)^{* *}$ \\
& 0.36 & 0.26 & 0.24 \\
Values Congruency & $(7.91)^{* *}$ & $(4.72)^{* *}$ & $(4.51)^{* *}$ \\
& & 0.18 & 0.12 \\
Altruistic Motivation & & $(3.18)^{* *}$ & $(2.16)^{*}$ \\
Adjusted R & & & 0.24 \\
& & & $(5.46)^{* *}$ \\
& 0.424 & 0.438 & 0.481 \\
\hline
\end{tabular}

\begin{tabular}{ll}
\hline$*$ & denotes significant at 0.01 level \\
$*$ & denotes significant at 0.05 level
\end{tabular}


Table 2: Importance of various motives for volunteer retention

\begin{tabular}{lc}
\hline Volunteer Motive to Stay & $\begin{array}{c}\text { Five Point } \\
\text { Rating }\end{array}$ \\
\hline The organization has a great cause (purpose) & 4.52 \\
Giving service to the community & 4.45 \\
\hline A compassion to help people & 4.41 \\
Reputation and good standing of the organization & 4.18 \\
Meeting with interesting members of the public/ clients & 4.02 \\
Pleasant working conditions & 3.85 \\
\hline The work allows me to use my expertise and experience & 3.82 \\
\hline
\end{tabular}


Table 3: Multiple Regression Model of Volunteer Continuance by Tenure Phase Dependent variable: Intention to remain in the nonprofit organization

\begin{tabular}{|c|c|c|c|c|}
\hline Antecedents & $\begin{array}{l}\text { Tenure } \\
\text { Phase } 1 \\
\text { (1 Year) }\end{array}$ & $\begin{array}{c}\text { Tenure } \\
\text { Phase } 2 \\
\text { (2 Years) }\end{array}$ & $\begin{array}{c}\text { Tenure } \\
\text { Phase } 3 \\
\text { (3 \& } 4 \\
\text { Years) } \\
\end{array}$ & $\begin{array}{c}\text { Tenure } \\
\text { Phase } 4 \\
\text { (5 plus } \\
\text { Years) } \\
\end{array}$ \\
\hline \multirow[t]{2}{*}{ Altruistic Motivation } & 0.15 & 0.13 & 0.32 & 0.40 \\
\hline & $(1.98)^{*}$ & (1.22)n.s. & $(2.86) * * *$ & $(4.78)^{* * *}$ \\
\hline \multirow[t]{2}{*}{ Values Congruency } & 0.10 & 0.10 & 0.13 & 0.15 \\
\hline & (0.92)n.s. & (0.10)n.s. & (0.92)n.s. & (1.46)n.s. \\
\hline \multirow[t]{2}{*}{ Organizational Commitment } & 0.26 & 0.33 & 0.19 & 0.12 \\
\hline & $(2.73)^{* * *}$ & $(2.85)^{* * *}$ & (1.43)n.s. & $(1.25)$ n.s. \\
\hline \multirow[t]{2}{*}{ Volunteer Work Satisfaction } & 0.41 & 0.42 & 0.19 & 0.21 \\
\hline & $(4.56) * * *$ & $(4.18)^{* * *}$ & (1.52)n.s. & $(2.49)^{* *}$ \\
\hline \multirow[t]{2}{*}{ Adjusted $\mathbf{R}^{2}$} & 0.52 & 0.45 & 0.41 & 0.47 \\
\hline & $(\mathrm{F}=28.9)^{* * *}$ & $(\mathrm{~F}=15.2)^{* * *}$ & $(\mathrm{~F}=13.3)^{* * *}$ & $(\mathrm{~F}=24.7)^{* * *}$ \\
\hline \multicolumn{5}{|c|}{ *** $\quad$ denotes significant at 0.01 level } \\
\hline \multicolumn{5}{|c|}{ ** denotes significant at 0.05 level } \\
\hline \multicolumn{5}{|c|}{ * denotes significant at 0.10 level } \\
\hline n.s. denotes not significant & & & & \\
\hline
\end{tabular}


Table 4: Elevation of volunteer motive since recruitment (Respondents: $\mathbf{n}=357$ )

\begin{tabular}{|c|c|c|c|c|c|}
\hline Volunteer Motive & $\begin{array}{c}\text { Total } \\
\#\end{array}$ & $\begin{array}{l}\text { Tenure } \\
\text { Phase } 1 \\
\text { (1 Year) }\end{array}$ & $\begin{array}{c}\text { Tenure } \\
\text { Phase } 2 \\
\text { (2 Years) }\end{array}$ & $\begin{array}{c}\text { Tenure } \\
\text { Phase } 3 \\
(3 \& 4 \\
\text { Years }) \\
\end{array}$ & $\begin{array}{c}\text { Tenure } \\
\text { Phase } 4 \\
(5 \text { plus } \\
\text { Years) } \\
\end{array}$ \\
\hline Zero change in motive & 99 & 33 & 23 & 18 & 25 \\
\hline $\begin{array}{l}\text { The organization has a great } \\
\text { cause (purpose) }\end{array}$ & 39 & 10 & 8 & 9 & 12 \\
\hline $\begin{array}{l}\text { Giving service to the } \\
\text { community }\end{array}$ & 53 & 15 & 12 & 11 & 15 \\
\hline A compassion to help people & 58 & 14 & 9 & 12 & 23 \\
\hline $\begin{array}{l}\text { Reputation and good } \\
\text { standing of the organization }\end{array}$ & 4 & 1 & 1 & 1 & 1 \\
\hline $\begin{array}{l}\text { Meeting with interesting } \\
\text { members of the public/ } \\
\text { clients }\end{array}$ & 46 & 14 & 10 & 2 & 20 \\
\hline Pleasant working conditions & 3 & 3 & 0 & 0 & 0 \\
\hline $\begin{array}{l}\text { The work allows me to use } \\
\text { my expertise and experience }\end{array}$ & 17 & 4 & 1 & 5 & 7 \\
\hline $\begin{array}{l}\text { Opportunities to form } \\
\text { friendships }\end{array}$ & 11 & 3 & 1 & 4 & 3 \\
\hline $\begin{array}{l}\text { The work allows me to } \\
\text { develop my skills }\end{array}$ & 24 & 8 & 5 & 6 & 5 \\
\hline $\begin{array}{l}\text { Financial benefits (meals, } \\
\text { coffee, travel) }\end{array}$ & 2 & 0 & 0 & 2 & 0 \\
\hline
\end{tabular}

